\title{
BMJ Open Cross-sectional study of aggression against Spanish nursing personnel and effects on somatisation of physical symptoms
}

\author{
María del Carmen Pérez-Fuentes (D) , ,2 María del Mar Molero Jurado, ${ }^{1}$ \\ África Martos Martínez, ${ }^{1}$ María del Mar Simón Márquez, ${ }^{1}$ \\ Nieves Fátima Oropesa Ruiz, ${ }^{1}$ José Jesús Gázquez Linares ${ }^{1,3}$
}

To cite: Pérez-Fuentes MdC Molero Jurado MdM, Martos Martínez Á, et al. Crosssectional study of aggression against Spanish nursing personnel and effects on somatisation of physical symptoms. BMJ Open 2020;10:e034143. doi:10.1136/ bmjopen-2019-034143

- Prepublication history for this paper is available online. To view these files, please visit the journal online (http://dx.doi org/10.1136/bmjopen-2019034143).

Received 06 September 2019 Revised 24 January 2020 Accepted 12 February 2020

Check for updates

(C) Author(s) (or their employer(s)) 2020. Re-use permitted under CC BY-NC. No commercial re-use. See rights and permissions. Published by BMJ.

${ }^{1}$ Department of Psychology, University of Almeria, Almeria, Andalucía, Spain

${ }^{2}$ Universidad Politécnica y

Artística del Paraguay, Asuncion, Gran Asunción, Paraguay

${ }^{3}$ Universidad Autónoma de Chile, Temuco, Chile

Correspondence to Dr María del Carmen Pérez-

Fuentes; mpf421@ual.es,

Dr José Jesús Gázquez Linares; jlinares@ual.es and

Dr María del Mar Molero Jurado; mmj130@ual.es

\section{ABSTRACT}

Introduction Violence against nursing personnel in their place of work is a severe problem generating important consequences for these workers. Even though there is a large body of research on the subject, the emotional impact of aggression against healthcare workers continues to be debated.

Objectives The objective of this quantitative, observational cross-sectional study was to analyse the effects of aggression against nursing personnel and the mediating role of anxiety in somaticising physical symptoms.

Method The sample was made up of 1357 nursing professionals who answered questionnaires evaluating their sensitivity to anxiety and the presence of somatic symptoms.

Results Of the professionals who indicated that they had been the victims of aggression by family members or patients in the previous year, $52.8 \%$ said it had happened to them on one occasion, $25.2 \%$ had experienced two episodes, while $6.9 \%$ and $15.1 \%$ said they had undergone three or more aggressions, respectively. Although $89.3 \%$ of the professionals affected by acts of indicated that they had not undergone physical or psychological consequences, there was a higher prevalence of somatic alteration among workers who had been victims of violence in the workplace. Furthermore, aggression at work had a direct effect on physical somatisation, which in turn acted as a mediator in the level of anxiety of nursing professionals. Thus, aggression increased the level of anxiety of nurses through the appearance of somatic symptoms.

Conclusions The results are discussed based on some of the consequences that appeared after episodes of aggression in the healthcare sector and their relationship.

\section{INTRODUCTION}

Violence and aggression against healthcare personnel

Violence in the workplace refers to violent events, such as harassment, threats or physical aggression, which compromise workers'wellbeing in the job environment. ${ }^{1}$ In the hospital
Strengths and limitations of this study

- The low mean age of the participants limited the use of age and years of experience in analysing the development of violence in the workplace.

- Active attempts to recruit more male nurses as participants were unsuccessful.

- When the nursing professionals gave their reasons for why aggression appeared, almost half of the sample said there was no specific cause.

- Limitations include the cross-sectional nature of the study and omission of other variables, which could have been included, such as analysis of the causes of aggression.

- The study employed relational methods, enabling inclusion of a large number of predictor and other variables, and finding complex interactions between predictor variables, which could then be included in the model.

sector, such aggressive behaviour may come from patients, family members, colleagues or other professionals. ${ }^{23}$ Aggression by patients and family members is a continuous challenge to organisations and healthcare professionals. Nurses are affected mostly ${ }^{4}$ because they are in constant direct contact with patients. ${ }^{5}$ In the Spanish healthcare sector, patients, followed by their family members, are the main aggressors. ${ }^{6}$ This study, therefore, concentrated on aggression by the users and their relatives.

Aggression against the nursing staff is a severe, generalised problem, ${ }^{7}$ causing a negative impact on the healthcare system by damaging the quality of patient care, safety and the well-being of workers. ${ }^{18}$ Nursing professionals who have been victims of aggression in the workplace may suffer from stress, exhaustion, job dissatisfaction, lack of concentration, irritability and lowered 
productivity. ${ }^{9} 10$ These workers are also more likely to leave the healthcare profession, ${ }^{10}{ }^{11}$ which leads to strong economic consequences associated with violence in the workplace. $^{12}$

Some studies have shown that among the characteristics of the victims of job violence, it is the workers with the most experience who tend to undergo the most incidents of violence, ${ }^{13}$ while other authors have found stronger prevalence among the youngest professionals, due to their limited communication and conflict resolution skills. ${ }^{14} 15$ Regardless of years of experience, most of the recorded attacks on nurses occur when they are 30-50 years old. ${ }^{6}$ However, some studies, such as the one by Berlanda $e t$ $a l,{ }^{16}$ have shown that the age variable is negatively related to violence in the workplace, as those with the most years of experiences have mature management and communication skills for dealing with patients and visitors, thereby reducing confrontation. Most aggression against hospital staff is verbal, ${ }^{17}$ and the patient's family members are the main authors of non-physical violence, while physical assault is usually by the patients themselves. ${ }^{18}$

Aggression takes place most often in the hospital environment, and the largest number of violent episodes are reported in the geriatric, psychiatric and emergency units. ${ }^{15}$ Numerous studies have found this phenomenon to be especially prevalent in the emergency room, ${ }^{5} 7911$ 18-21 so much so that the emergency room staff takes aggression as an inevitable part of their work. ${ }^{22}$ Hospital situations in which the most aggressiveness appears are those where there is a strong emotional demand. ${ }^{23}$ The nursing activity with the most violent situations is triage, followed by communicating news to the patient. ${ }^{17}$ Other factors which the nursing staff perceive as potentially at risk of aggression are lack of security, receiving inadequate information about the patient, long waiting times and attending patients under the effects of alcohol or drugs. ${ }^{24-26}$ Absence of visible security staff, lack of training on how to react to aggression, a heavy workload and shortage of professionals are other variables, which often precede the appearance of violent behaviour in the workplace. ${ }^{27}$

The most common strategies and responses professionals use to cope with violent situations are to request help from a coworker, warn the hospital security chief $^{28}$ or tell a coworker about the violent incident later. ${ }^{18}$ Nurses consider improving communication with patients and the information given them, and enlarging the staff to be the most useful measures for reducing aggression in the workplace. ${ }^{18}$ More and more professionals are also demanding training in dealing with conflicts in the workplace. In this line, acquisition of physical and verbal defense skills against violence in the workplace has been shown to improve health workers' response and selfefficacy against aggression. ${ }^{20}$

\section{Anxiety and physical somatisation of healthcare workers}

The nursing staff confronts a multitude of situations, such as attending patients or demands of family members, which are a daily source of tension and stress. ${ }^{29}$ The presence of such stressors promotes psychophysiological responses which can affect their health. ${ }^{30}$ In spite of the importance of research related to anxiety, there are few studies analysing the nature and strength of the relationship between anxiety and physical health problems in adulthood. ${ }^{31}$ Some of the most intense physical symptoms associated with anxiety are respiratory and stomach problems, cardiac alterations, migraine, menstrual pain, thyroid and psoriasis. ${ }^{32-35}$ Anxiety has also been linked to the presence of somatic symptoms typical of chronic fatigue syndrome, generalised chronic pain (fibromyalgia) and irritable intestine syndrome, ${ }^{36}$ as well as unspecified chronic arm and neck pain. ${ }^{37}$ These somatic symptoms are usually frequent and often require a specialist's intervention. ${ }^{32}$ The psychosomatic health of nursing professionals is closely related to the results of their work. ${ }^{38}$ Therefore, somatic symptoms associated with their loss of health, such as chronic fatigue, generate a decrease in their healthcare performance and high costs for society as a whole. ${ }^{3940}$

However, the direction of the association between anxiety and somatic physical symptoms continues to be discussed. Some authors, such as Dijkstra-Kersten et $a l^{41}$ note that somatisation in adulthood increases the risk of developing a depressive or anxiety disorder. Thus, people who tend to feel and talk about symptoms not associated with any pathology, have a higher incidence of anxiety and depression in later years. On the contrary, other studies have shown that anxiety predicts an increase in physical symptomatology in the months following its appearance. ${ }^{31}$ An intermediate position is the one taken by Creed $e t a l,{ }^{36}$ who suggested that emotional disorders, such as depression or anxiety, as well as the presence of medical illnesses and anxiety about one's own health predict the appearance of somatic symptoms, which in turn, generate deterioration in health. Thus, anxiety would provoke development of somatic symptoms which worsen the individual's health, and this in turn, leads to new states of anxiety and somatisation.

\section{Effects of aggression on anxiety and somatisation in nursing} Aggression against healthcare professionals has a negative social and professional impact, and affects the worker's health. ${ }^{5}$ Nursing staff who have been the victim of violence in the workplace complain of psychological and physical problems, such as muscular and bone injuries, problems sleeping, chronic pain, depression and unpleasant emotions. ${ }^{9}$ These negative feelings, and as a consequence, intention of quitting their job, appear mostly in professionals with little experience who are still less able to manage such situations. ${ }^{132}$

Being the victim of aggression in the hospital setting is associated with a higher risk of psychiatric morbidity. ${ }^{4}$ This has been shown by evidence that exposure to very severe psychological traumas can lead to development of post-traumatic stress disorder (PTSD) ${ }^{43}$ Exposure to severely violent situations is considered an antecedent 
traumatic event for stressful factors that promote development of PTSD, depression and anxiety. ${ }^{44}$ Even though violence and threats in the workplace are usually not as severe, they are often prolonged or repeated, which can contribute to increasing the risk of mental disorders. ${ }^{45} 46$ The appearance of episodes of violence in the workplace has been specifically related to development of PTSD symptoms, ${ }^{47} 48$ as well as presence of anxiety, physical symptoms and sleep impairment in healthcare professionals. ${ }^{49}{ }^{50}$ The study by Shi $e t a l{ }^{51}$ in a sample of doctors and nurses, showed that professionals who had experienced violence in the workplace in the past year were more prone to symptoms of anxiety than those who had not, especially nurses. There is, therefore, a positive association between the presence of hospital aggression and the level of anxiety of nursing professionals. ${ }^{52} 53$

The first reaction of the majority of healthcare professionals to violence in the workplace is a negative emotional response, followed by physiological symptoms (gastrointestinal problems, nighttime restlessness and insomnia, sudden crying and panting) and later emotional responses, such as feeling guilty. ${ }^{28}$ Fear of reappearance of violent episodes in the future has also been linked to emotional exhaustion among workers in the healthcare sector, ${ }^{545}$ which in turn, is associated with a feeling of job insecurity. ${ }^{56}$ Meanwhile, practising the healthcare profession in healthy settings is associated with less risk of this syndrome appearing. ${ }^{57}{ }^{58}$ In spite of increasing evidence of the implications for the physical and psychological health of the workers appearing some time after the assault, the indirect economic load it generates has not yet been accounted for. ${ }^{12}$

According to Giannouli, ${ }^{59}$ the influence of individual factors, such as personality, perception and experience with violence, ${ }^{60}$ trait anxiety $^{61}$ or the level of emotional intelligence $^{62}$ on psychological phenomena, must also be considered when studying the factors associated with the appearance and consequences of violence on nursing professionals in the workplace. However, the emotional impact of aggression on worker health must be treated as a major theme in research on violence in the work environment. ${ }^{63}$ Ramacciati $e t a l^{7}$ suggested that although there is a considerable body of knowledge on violence against nursing personnel, information is still lacking, and a multifactor perspective must be taken to improve understanding of the problem as part of the growing attention to mechanisms promoting health and wellbeing of nursing professionals. ${ }^{64}$ Therefore, the objective of this study was to analyse the effects of aggression on nursing personnel and the mediating role of anxiety with regard to somatisation of physical symptoms.

\section{METHOD}

\section{Participants}

Of the original sample of 1627 Spanish nurses, only those residing in the Region of Andalusia at the time data were acquired were selected $(n=1377)$. The aggression in healthcare report, which stated that in 2018 almost 1500 cases of aggression were reported by nursing personnel, most of which were concentrated in Andalusia ${ }^{65}$ Furthermore, 20 of these were discarded because of incongruencies or random answers, leaving a final study sample of 1357 participants.

The mean participant age was $30.86(\mathrm{SD}=6.09)$, in a range of 22-58. Of the total sample, $83.9 \%(\mathrm{n}=1138)$ were women and $16.1 \%(\mathrm{n}=219)$ men, with a mean age of 30.80 $(\mathrm{SD}=6.12)$ and 31.15 ( $\mathrm{SD}=5.92)$, respectively. Employment status at the time data were collected was $23.1 \%$ $(\mathrm{n}=313)$ on a permanent contract, $72.2 \%(\mathrm{n}=980)$ temporary and the remaining $4.7 \%(\mathrm{n}=64)$ were unemployed.

\section{Instruments}

An ad hoc questionnaire was prepared to collect sociodemographic data (age and sex) and information on current employment. Some questions on whether subjects had ever undergone aggression as a consequence of their service were extracted from the survey on aggression against nursing personnel used by Travetto et al. ${ }^{66}$ If an answer was affirmative, it was followed by questions about the frequency, type (verbal/physical by patients/family members), context of the aggression, response, consequences of the aggression received and their perception of security in the workplace. Before its implementation, the ad hoc questionnaire was applied in a pilot test to a sample with similar characteristics $(n=30)$. Appropriate modifications were then made to it based on problems found.

Anxiety Sensivity Index-3 (ASI-3): ${ }^{67}$ The Spanish version by Sandín $e t a t^{68}$ was used. This scale consists of 18 items referring to fear/anxiety reactions to physical symptoms, loss of cognitive control and visible symptoms experienced in social situations. The answers are rated on a 5-point Likert type scale, where $0=$ very little or almost not at all and $4=$ verymuch. It provides scores on three subscales (physical, cognitive and social) and a general index of sensitivity to anxiety. In this study, the ordinal alpha was 0.93 in physical anxiety, 0.94 in cognitive anxiety and 0.86 in social anxiety.

The Physical Health Questionnaire (PHQ): ${ }^{69}$ A brief version of the questionnaire, revised by Schatet $a l^{70}$ was used. It consists of 14 items asking about the frequency of sleep disorders, headaches, respiratory infections and gastrointestinal problems. Items $1-11$ are answered on a 7 -point Likert type scale (from $1=$ never to $7=$ all the time), and the rest (12-14) have other answer choices related to frequency. In their PHQ validation study, Schat $e t a l^{70}$ found acceptable internal consistency for the dimensions, but a lower alpha for the respiratory infection subscale $(\alpha=0.66)$. In this study, the ordinal alpha calculated was: 0.81 for sleep disturbance, 0.91 for headaches, 0.90 for gastrointestinal problems and 0.64 for respiratory illness.

\section{Procedure}

To acquire the data, the investigators first contacted a Spanish scientific society whose staff then worked in 
conjunction with the research team to inform healthcare professionals about the study and to request their participation, which was totally voluntary, individual and anonymous.

Before beginning the questionnaire, participants were guaranteed compliance with the standards of information, confidentiality and ethics in data processing. The questionnaires were implemented on a Web platform which enabled them to be filled in online. Questionnaires with random or incongruent answers, found through a series of control questions included in them, were discarded from the study sample. The data were compiled from January to September 2018. The questionnaire took an estimated $35 \mathrm{~min}$ to complete. Patients were not involved in this research.

\section{Data analysis}

This study was quantitative, observational and crosssectional. First, a frequency analysis was performed to find the subsample of professionals who had undergone aggression. Then, to explore the relationships between variables, a correlation analysis and Student's t-test were performed for between-group analysis of the group of professionals who had undergone aggression and the group who had not, and Cohen's $d^{71}$ to test for the effect size of the differences found. The SPSS V.23.0 statistical package for Windows was used for data processing and analysis.

In addition, in view of the proposal of two mediation hypotheses, simple mediation analyses were done. In both cases, the predictor variable was experiencing aggression or not. In the first calculation of the mediation models, the dependent variable was presence of physical symptomatology (four types), and in the second, the general index of sensitivity to anxiety. The SPSS macro for mediation models ${ }^{72}$ was used for this, with bootstrap estimates of coefficients with 5000 bootstrap samples.

To examine the reliability of the instruments used for data collection, the following procedure was used to estimate the internal consistency of the scores: (1) first, an exploratory factor analysis was carried out on the polychoric correlation matrix, using FACTOR software. ${ }^{73}$ The data were computed with parametric analysis and promin rotation. 2) The Excel spreadsheet developed by Domínguez-Lara ${ }^{74}$ was used to calculate the alpha ordinal coefficient based on polychoric correlation analysis, and which is therefore more suitable for calculating the reliability of scales with an ordinal or Likertscale response. ${ }^{75}$ Reliability of the measures was tested by the split-half method, ${ }^{76}$ which consists of regrouping the items in two parts and comparing the relationship between the two halves. The Spearman-Brown correlation coefficient was 0.91 for the ASI-3 and 0.73 for the PHQ.

Patient and public involvement

No patients were involved.
RESULTS

Aggression against healthcare personnel: analysis of frequencies and descriptive statistics

Of the sample evaluated, $11.8 \% \quad(n=159)$ said they had undergone some type of aggression as the consequence of their service. Aggression was defined as violent episodes experienced as a result of care work. These episodes may have been oral (eg, insults, shouting, defamation, ridiculing or intimidation) or physical (eg, cornering, pushing, hitting or attacking with an object) ${ }^{66}$ During the preceding year, 52.8\% ( $\mathrm{n}=84)$ had experienced one episode, $25.2 \%(\mathrm{n}=40)$ on two, $6.9 \%(\mathrm{n}=11)$ three, and $15.1 \%(\mathrm{n}=24)$ more than three.

No statistically significant differences were found in sex of those assaulted, although there were in age, with more professionals over $30(64.2 \%, \mathrm{n}=102) \quad\left(\chi^{2}=11.05, \mathrm{p}<0.01\right)$ than younger $(35.8 \%, \mathrm{n}=57)$.

Aggression was verbal abuse by patients in $87.4 \%$ $(\mathrm{n}=139)$ and $74.2 \% \quad(\mathrm{n}=118)$ by family members, while physical aggression was by patients in $35.8 \%(n=57)$ of the cases and $5.7 \%(n=9)$ was by family members.

The context of the aggression was mostly in hospital units, the emergency room in $40.3 \%(n=64)$ of the cases and in the wards $36.5 \%(\mathrm{n}=58) .37 .7 \%(\mathrm{n}=60)$ were alone at the time of the aggression and $62.3 \%(\mathrm{n}=99)$ in the presence of other staff members.

In $91.2 \% \quad(n=145)$ of the cases, the aggressor was by a single person, while in $8.8 \% \quad(n=14)$ of the cases, the aggression was by a group.

The aggression was triggered in $42.1 \% \quad(n=67)$ of the cases by delayed attention. Less frequently it was sparked by lack of resources for solving a clinical problem $(10.1 \%$, $\mathrm{n}=16)$ or after communicating a death $(0.6 \%, \mathrm{n}=1)$. The remaining $47.2 \% \quad(n=75)$ were for other unspecified reasons.

In response to the aggression, $49.7 \% \quad(n=79)$ said they had controlled the situation through dialogue, $31.4 \%$ $(n=50)$ called colleagues or security personnel, $14.5 \%$ $(\mathrm{n}=23)$ walked away and $4.4 \%(\mathrm{n}=7)$ did not say how they reacted.

As a consequence of the aggression received, 10.7\% $(n=17)$ were injured or had some type of physical or psychological consequence, whereas $89.3 \%(n=142)$ said they had no injuries or other consequences.

The professionals who had undergone aggression were also asked if there were security personnel at their workplace, to which $64.2 \%(\mathrm{n}=102)$ answered affirmatively. Finally, when the professionals were asked about their perception of security in the workplace, $62.9 \% \quad(n=100)$ of those who had been assaulted said they felt safe.

\section{Aggression, presence of physical symptoms and sensitivity to anxiety}

As observed in table 1, the frequency of aggression in the past year did not correlate with age, anxiety or with any of the aspects related to physical symptomatology.

Age correlated negatively with cognitive and social anxiety, as well as with the global anxiety score. Physical 
Table 1 Aggression frequency, anxiety and physical symptoms

\begin{tabular}{|c|c|c|c|c|c|c|c|c|c|c|}
\hline & 1 & 2 & 3 & 4 & 5 & 6 & 7 & 8 & 9 & 10 \\
\hline 1.AGG & - & & & & & & & & & \\
\hline 2.Age & -0.02 & - & & & & & & & & \\
\hline 4.C_ANX & 0.08 & $-0.07^{\star \star}$ & $0.83^{\star \star \star}$ & - & & & & & & \\
\hline 5.S_ANX & 0.09 & $-0.09^{\star \star \star}$ & $0.67^{\star \star \star}$ & $0.68^{\star \star \star}$ & - & & & & & \\
\hline 7.GASTR & 0.12 & $-0.06^{*}$ & $0.28^{\star \star \star}$ & $0.28^{\star \star \star}$ & $0.27^{\star \star \star *}$ & $0.31^{\star * \star *}$ & - & & & \\
\hline 8.HEAD & 0.02 & $-0.05^{\star}$ & $0.25^{\star \star \star}$ & $0.27^{\star \star \star}$ & $0.31^{\star \star \star}$ & $0.31^{\star \star \star \star}$ & $0.54^{\star \star \star}$ & - & & \\
\hline 9.SLEEP & 0.12 & 0.00 & $0.26^{\star \star \star}$ & $0.28^{\star * \star}$ & $0.26^{\star * *}$ & $0.30^{\star \star \star}$ & $0.44^{\star \star \star}$ & $0.48^{\star \star \star}$ & - & \\
\hline 10.RESP & 0.08 & -0.01 & $0.21^{\star \star \star}$ & $0.19^{\star \star \star}$ & $0.19^{\star \star \star}$ & $0.22^{\star \star \star}$ & $0.30^{\star \star \star}$ & $0.30^{\star \star \star}$ & $0.24^{\star * \star}$ & - \\
\hline
\end{tabular}

Bivariate correlations.

${ }^{*} \mathrm{P}<0.05 ;{ }^{* *} \mathrm{P}<0.01 ;{ }^{* \star *} \mathrm{P}<0.001$.

AGG, aggression frequency; ANX, global anxiety; C_ANX, cognitive anxiety; GASTR, gastrointestinal problems; HEAD, headaches; P_ANX, physical anxiety;; RESP, respiratory illness; S_ANX, social anxiety; SLEEP, sleeping problems.

symptomatology, gastrointestinal problems and headaches were negatively related to age, such that the older the professional was, the less presence of symptomatology.

Anxiety correlated positively with the presence of physical symptomatology (gastrointestinal problems, headaches, sleeping problems and respiratory infections). These relationships were present in each of the dimensions of anxiety (physical, cognitive and social) and also global anxiety. Different physical symptomatology variants were also observed to correlate positively with each other.

When the groups of professionals who had experienced aggression at some time were compared with those who had not, statistically significant differences were observed in the physical symptoms present. Specifically, those who had been assaulted showed more symptomatology than the rest of professionals. No significance was observed in the comparison of mean scores of the two groups in sensitivity to anxiety (table 2).

\section{Mediation models}

Based on the results above, we posed a question with two possible answers: Is sensitivity to anxiety what mediates in the aggression frequency (AGG) presence of symptomatology relationship? Or is it the presence of symptomatology which acts as the mediator on the effect of having been assaulted and sensitivity to anxiety? To clarify the relationships between variables and determine the position of the variables in the model, a series of mediation analyses was performed with the results described below.

First, with regard to the first mediation hypothesis $\left(\mathrm{MH}_{1}\right.$ : sensitivity to anxiety acts as the mediator in the relationship between experiencing aggression and the presence of physical symptomatology), simple mediation

Table 2 Anxiety and physical symptoms

\begin{tabular}{|c|c|c|c|c|c|c|c|c|c|}
\hline & \multicolumn{6}{|c|}{ Have you ever been assaulted as a consequence of your service? } & \multirow[b]{3}{*}{$\begin{array}{lll}T & \end{array}$} & \multirow[b]{3}{*}{$P$ value } & \multirow[b]{3}{*}{ D } \\
\hline & \multicolumn{3}{|l|}{ No } & \multicolumn{3}{|l|}{ Yes } & & & \\
\hline & $\mathbf{N}$ & $\mathbf{M}$ & SD & $\mathbf{N}$ & M & SD & & & \\
\hline P_ANX & 1193 & 3.67 & 4.55 & 159 & 3.85 & 4.47 & -0.45 & 0.646 & - \\
\hline C_ANX & 1193 & 2.75 & 4.02 & 159 & 3.25 & 4.21 & -1.45 & 0.146 & - \\
\hline S_ANX & 1193 & 6.41 & 4.49 & 159 & 6.95 & 4.18 & -1.43 & 0.151 & - \\
\hline ANX & 1193 & 12.83 & 11.85 & 159 & 14.05 & 11.63 & -1.21 & 0.224 & - \\
\hline GASTR & 1193 & 2.47 & 1.18 & 159 & 2.79 & 1.28 & $-2.99^{* *}$ & 0.003 & 0.25 \\
\hline HEAD & 1193 & 2.79 & 1.30 & 159 & 3.12 & 1.43 & $-2.90^{* *}$ & 0.004 & 0.25 \\
\hline SLEEP & 1193 & 3.09 & 1.12 & 159 & 3.42 & 1.24 & $-3.22^{* *}$ & 0.001 & 0.27 \\
\hline RESP & 1193 & 2.30 & 0.94 & 159 & 2.45 & 0.98 & $-1.97^{*}$ & 0.048 & 0.17 \\
\hline
\end{tabular}

Descriptive and $t$ test by aggression (assaulted/not assaulted).

${ }^{\star} \mathrm{P}<0.05 ;{ }^{* *} \mathrm{P}<0.01 ;{ }^{* *} \mathrm{P}<0.001$.

ANX, global anxiety; C_ANX, cognitive anxiety; GASTR, gastrointestinal problems; HEAD, headaches; P_ANX, physical anxiety; RESP, respiratory illness; S_ANX, social anxiety; SLEEP, sleeping problems. 
( $Y$ ) $(X \rightarrow Y)$

$(M \rightarrow Y)$

( $Y)$

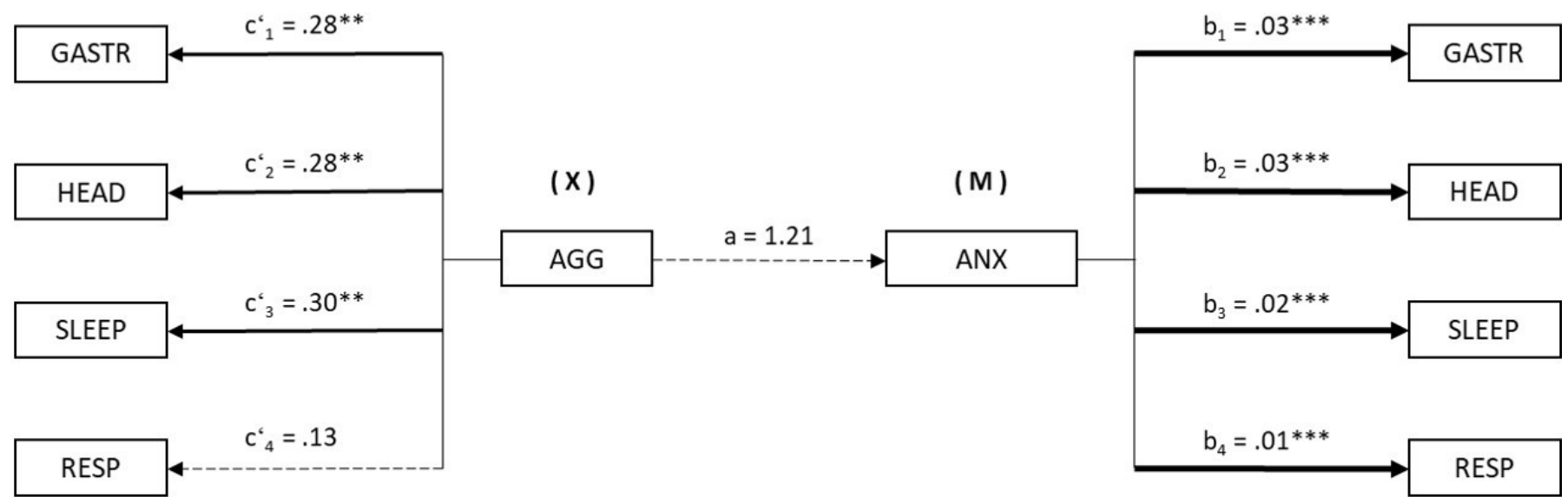

Figure 1 Mediation model of sensitivity to anxiety on the relationship between aggression and the presence of physical symptomatology $\left(\mathrm{MH}_{1}\right)$. AGG, aggression frequency; $\mathrm{ANX}$, global anxiety; $\mathrm{MH}$, mediation hypothesis. ${ }^{* \star} \mathrm{P}<0.01 ;{ }^{* \star \star} \mathrm{P}<0.001$.

models were computed for the types of symptomatology, where the predictor variable was aggression, and in all cases, sensitivity to anxiety was entered as the mediator (for mediation models, the global index of sensitivity to anxiety was used).

As observed in figure 1 , the effect of aggression (X) on anxiety as the mediator variable $(B=1.21, p=0.223)$ was not significant. In the following regression analysis, taking each of the types of physical symptomatology as the result variables (Y), the effects of the independent variable (shown in the left-hand column $\mathrm{X} \rightarrow \mathrm{Y}$ ) and the mediator (shown in the right-hand column: $\mathrm{M} \rightarrow \mathrm{Y}$ ) were estimated.

The estimation of the direct effects $\mathrm{X} \rightarrow \mathrm{Y}$ showed that aggression was significant on: GASTR $(B=0.28, p<0.01)$, HEAD $(\mathrm{B}=0.28, \mathrm{p}<0.01)$ and SLEEP $(\mathrm{B}=0.30, \mathrm{p}<0.01)$, but not the effect of aggression on RESP, where it was only tendential $(\mathrm{B}=0.13, \mathrm{p}=0.080)$. Furthermore, when the $\mathrm{M} \rightarrow \mathrm{Y}$ effects were estimated, the effect of anxiety (M) on physical symptomatology was significant in all cases:
GASTR ( $\mathrm{B}=0.03, \mathrm{p}<0.001)$, HEAD $(\mathrm{B}=0.03, \mathrm{p}<0.001)$, SLEEP $(\mathrm{B}=0.02, \mathrm{p}<0.001)$ and $\operatorname{RESP}(\mathrm{B}=0.01, \mathrm{p}<0.001)$.

The analysis of indirect effects $(\mathrm{X} \rightarrow \mathrm{M} \rightarrow \mathrm{Y})$ with bootstrapping did not show significance in any of the assumptions: GASTR $(\mathrm{B}=0.03, \mathrm{SE}=0.03,95 \% \mathrm{CI}(-0.01$ to 0.10$))$, HEAD $(\mathrm{B}=0.04, \mathrm{SE}=0.03,95 \% \mathrm{CI}(-0.02$ to 0.11$))$, SLEEP $(\mathrm{B}=0.03, \mathrm{SE}=0.02,95 \% \mathrm{CI}(-0.01$ to 0.09$))$ or RESP $(\mathrm{B}=0.02, \mathrm{SE}=0.01,95 \% \mathrm{CI}(-0.01$ to 0.06$))$.

For the second mediation hypothesis proposed $\left(\mathrm{MH}_{2}\right.$ : presence of physical symptomatology mediates in the relationship found between having undergone aggression and sensitivity to anxiety), simple mediation analyses were performed. In all cases, the predictor variable was aggression (X), sensitivity to anxiety was the dependent variable $(\mathrm{Y})$ and the types of physical symptomatology $\left(\mathrm{M}_{1}, \mathrm{M}_{2}, \ldots\right)$ were entered as the mediator variable in each of the models.

Figure 2 shows the results of the four simple mediation models in which presence of physical symptoms was proposed as the mediator. First, significant effects

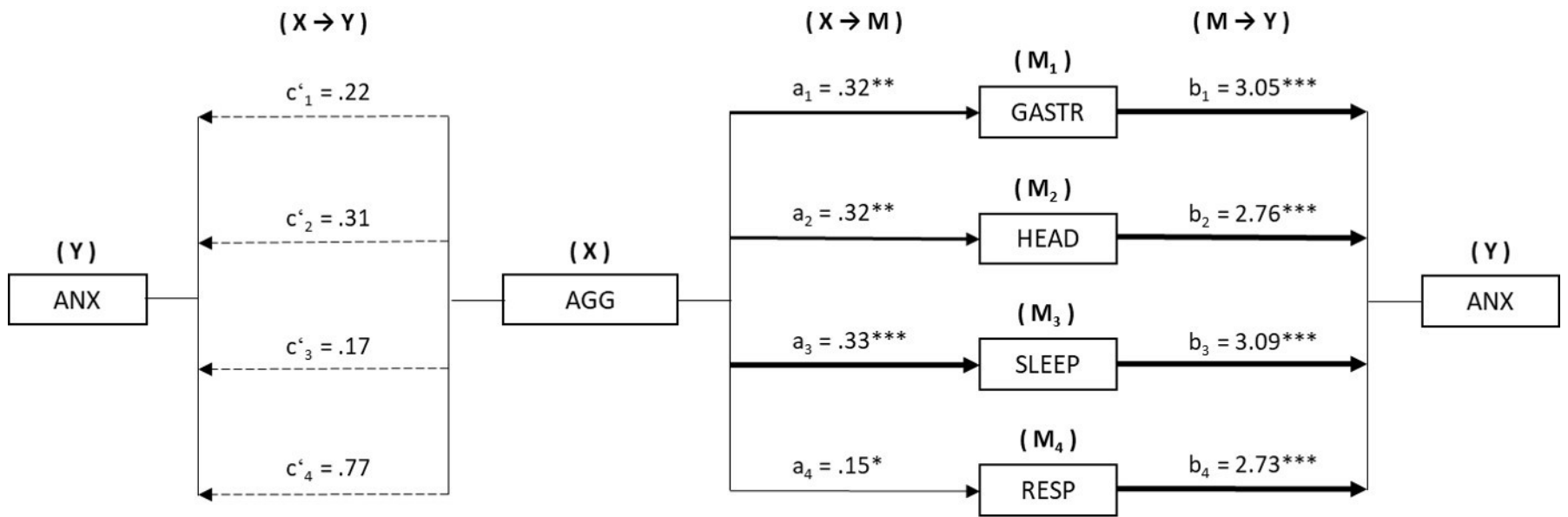

Figure 2 Mediation model of the presence of physical symptomatology on the relationship between aggression and sensitivity to anxiety $\left(\mathrm{MH}_{2}\right)$. AGG, aggression frequency; ANX, global anxiety; $\mathrm{MH}$, mediation hypothesis. ${ }^{\star} \mathrm{P}<0.05 ;{ }^{\star \star} \mathrm{P}<0.01 ;{ }^{\star \star \star} \mathrm{P}<0.001$. 
of aggression (X) on the physical symptoms (M) were observed: GASTR $(\mathrm{B}=0.32, \mathrm{p}<0.01)$, HEAD $(\mathrm{B}=0.32$, $\mathrm{p}<0.01)$, SLEEP $(\mathrm{B}=0.33, \mathrm{p}<0.001)$ and RESP $(\mathrm{B}=0.15$, $\mathrm{p}<0.05)$. The results of estimating the direct effects $(\mathrm{X} \rightarrow \mathrm{Y})$ reveal that there were no significant effects of aggression on anxiety in the computation of any of the models.

The estimation of $\mathrm{M} \rightarrow \mathrm{Y}$ found a significant effect of each of the physical symptoms on sensitivity to anxiety: GASTR $(\mathrm{B}=3.05, \mathrm{p}<0.001$, HEAD $(\mathrm{B}=2.76, \mathrm{p}<0.001)$, SLEEP $(B=3.09, p<0.001)$ and RESP $(B=2.73, p<0.001)$.

Finally, the analysis of indirect effects $(X \rightarrow M \rightarrow Y)$ using bootstrapping found significant values in all four models computed: GASTR $(\mathrm{B}=0.98, \mathrm{SE}=0.34,95 \%$ CI $(0.37$ to $1.70)$ ), HEAD ( $\mathrm{B}=0.89, \mathrm{SE}=0.34,95 \% \mathrm{CI}(0.27$ to 1.64$)$ ), SLEEP ( $\mathrm{B}=1.04, \mathrm{SE}=0.34,95 \% \mathrm{CI}(0.41$ to 1.79$))$ and $\operatorname{RESP}(\mathrm{B}=0.43, \mathrm{SE}=0.23,95 \%$ CI $(0.01$ to 0.93$))$.

\section{DISCUSSION}

Aggression in the workplace is a widespread problem among nurses. ${ }^{7}$ The findings of this study showed that over 10 out of 100 workers in the sector had been victims of assault in the performance of their service. This violence was more prevalent among professionals over 30 years of age who were working in the emergency room. These results are in agreement with the literature where this area has been postulated as the one where aggression toward healthcare professionals is most frequent. ${ }^{579} 1018-21$ In addition, as mentioned above, nursing professionals over the mean age of the sample were those who most said they had been victims of violence in the workplace. This was also true in the study by Li et al, ${ }^{13}$ who found that workers with the most experience were those who had undergone the most violent incidents.

With regard to the characteristics of the aggression, most of the assaults were verbal and mainly by the patients, followed by family members. Although according to Noorana and Feng, ${ }^{18}$ the authors of this type of assault are mainly family members, most of the violence against nursing professionals in the literature is verbal. ${ }^{17}$

There was less physical violence and this was caused mostly by patients, which coincides with previous studies. ${ }^{18}$ At the time of the assault, the professionals were usually with a coworker and the main cause was delay in care. This long waiting time was identified by nurses as a situation which frequently precedes appearance of violent behaviour in healthcare. ${ }^{27}$ Professionals usually coped with violent situations with dialogue, by calling a colleague or security. The latter has been pointed out in other studies as the most common strategy of nursing personnel for coping with violent situations,${ }^{28}$ while in this study, they said that their main tool for controlling such situations was dialogue, which may be because most of them experienced aggression while with another worker.

Nursing personnel also think communication is one of the main ways for reducing aggression, ${ }^{18}$ and the demand for training in this type of nontechnical skill for tackling violence is growing. However, beyond a description of violence in the workplace in the nursing sector, the first objective of this study was to analyse the effect of the aggression on these workers. According to the results, most of the professionals affected by assault said they had not suffered any physical or psychological consequences after aggression. However, a higher prevalence of gastrointestinal problems, respiratory symptoms, headaches and sleeping problems was found among workers who had undergone violent situations in the workplace than those who had not. This finding agrees with previous studies which have reported health problems of nurses who had been victims of job violence. ${ }^{9} 284$

The second objective of this study was to analyse the mediating role of anxiety in somatisation of physical symptoms. To respond to this objective, two possible mediation paths were proposed, sensitivity to anxiety as the mediator in the relationship between job aggression and presence of physical symptomatology or physical symptoms as mediators on the level of anxiety of those assaulted. In the light of the results, we can state that having been the victim of aggression in the workplace and the level of anxiety had a direct effect on somatisation of physical symptoms, but there were no mediation effects. However, there were mediation effects in the second path proposed, in which aggression at work had a direct effect on physical somatisation, which in turn acted as a mediator on the level of anxiety of nursing professionals. Therefore, as other authors have also found, violence in the work environment generates a negative impact on the psychological health of nursing personnel, ${ }^{5253}$ and physical symptoms appear after the assault, increasing anxiety. ${ }^{41}$ Thus, the stressful factors that follow violence would increase risk of appearance of anxiety in employees. ${ }^{44}$ This may be due, as suggested by Creed et $a l^{36}$ to medical problems leading to increased anxiety in adults, and this anxiety from health problems leads to further increases in the degree of anxiety.

\section{Limitations}

This study had some limitations, such as the low mean age of the participants, which limited evaluation of the involvement of age and years of experience in development of violence in the workplace. Furthermore, when the nursing professionals were asked their reasons for the aggression, almost half of the sample said there was no specific cause. This result limits knowledge of the causes of much of aggression. Future studies should provide more answer choices on this item or transform it into an open question that can provide more information. Furthermore, as evaluation used self-report questionnaires, the professionals' perception of the incidents may have influenced a decrease in the number of attacks reported by minimising their importance. Therefore, future studies should complete the evaluation with qualitative techniques, such as focus groups or interviews, which could help refine it. We should also emphasise that the appearance of somatic symptoms may be related to other highly 
stressful events in the job context, such as burnout or role stress, and so the findings should be interpreted with caution. The job context in healthcare is one of the most affected by the burnout syndrome, so psychosomatisation may be partly related to employee exhaustion. An additional limitation refers to the research method, which was cross-sectional and exploratory, and did not enable causal relationships or the long-term effect of the variables analysed to be established. Future studies should, therefore, include longitudinal evaluation of the professionals to find out the intensity and duration of somatic symptoms and the anxiety generated after violent episodes in the workplace.

\section{CONCLUSIONS}

Due to the socioeconomic implications of job violence in the healthcare sector, there is growing concern about this problem. The consequences of aggression at work for professionals, patients and the organisation, along with the increase in attention to mechanisms that promote the well-being of employees, justify the need for finding out the factors involved. This study has shown that aggression against nurses has a direct effect on the appearance of physical symptoms. This also affects the level of their anxiety. Thus, aggression at work increases anxiety of nurses, however, not directly, but through the appearance of physical symptoms, such as headaches, sleeping problems, respiratory and gastrointestinal problems.

This study defends the need to continue inquiring into the factors involved in aggression against nurses in the workplace and the variables related to its consequences. In-depth knowledge of this problem can lead to action initiatives for eliminating it from our hospitals.

Acknowledgements The present study was undertaken in collaboration with the Almeria Provincial Government. Part of the work received funding from Gerty Cori Aid for University Teaching Training in Deficit Areas granted María del Mar Simón Márquez for assistance in hiring predoctoral research staff.

Contributors MdMMJ, MdCP-F, MdMSM and AMM contributed to the conception and design of the review. JJGL applied the search strategy. All authors applied the selection criteria. All authors completed the assessment of bias risk. All authors analysed and interpreted the data. MdMMJ, MdCP-F, NFOR and AMM wrote this manuscript. MdCP-F and JJGL edited this manuscript. MdMMJ is responsible for the overall project.

Funding Part of the work received funding from Gerty Cori Aid for University Teaching Training in Deficit Areas granted MdMSM for assistance in hiring predoctoral research staff.

Competing interests None declared.

Patient consent for publication Not required.

Ethics approval The Bioethics Committee of the University of Almeria approved the study (Ref: UALBI02017/011).

Provenance and peer review Not commissioned; externally peer reviewed.

Data availability statement Data are available on reasonable request. Data may be obtained on request from a third party but are not publicly available.

Open access This is an open access article distributed in accordance with the Creative Commons Attribution Non Commercial (CC BY-NC 4.0) license, which permits others to distribute, remix, adapt, build upon this work non-commercially, and license their derivative works on different terms, provided the original work is properly cited, appropriate credit is given, any changes made indicated, and the use is non-commercial. See: http://creativecommons.org/licenses/by-nc/4.0/.

\section{ORCID iD}

María del Carmen Pérez-Fuentes http://orcid.org/0000-0001-5950-5175

\section{REFERENCES}

1 Lu L, Dong M, Wang S-B, et al. Prevalence of workplace violence against health-care professionals in China: a comprehensive meta-analysis of observational surveys. Trauma Violence Abuse 2018;19:1-9.

2 Abed M, Morris E, Sobers-Grannum N. Workplace violence against medical staff in healthcare facilities in Barbados. Occup Med 2016;66:580-3.

3 Park M, Cho S-H, Hong H-J. Prevalence and perpetrators of workplace violence by nursing unit and the relationship between violence and the perceived work environment. J Nurs Scholarsh 2015;47:87-95.

4 Groenewold MR, Sarmiento RFR, Vanoli K, et al. Workplace violence injury in 106 US hospitals participating in the occupational health safety network (OHSN), 2012-2015. Am J Ind Med 2018;61:157-66.

5 Han C-Y, Lin C-C, Barnard A, et al. Workplace violence against emergency nurses in Taiwan: a phenomenographic study. Nurs Outlook 2017;65:428-35.

6 Serrano MI, Fernández MT, Satústegui PJ, et al. Agresiones a profesionales del sector sanitario en España: Revisión Sistemática. Rev Esp Salud Pública 2019;93:e1-16.

7 Ramacciati N, Ceccagnoli A, Addey B, et al. Violence towards emergency nurses: a narrative review of theories and frameworks. Int Emerg Nurs 2018;39:2-12.

8 Liu J, Zheng J, Liu K, et al. Workplace violence against nurses, job satisfaction, burnout, and patient safety in Chinese hospitals. Nurs Outlook 2019;67:558-66.

9 Hassankhani H, Parizad N, Gacki-Smith J, et al. The consequences of violence against nurses working in the emergency department: a qualitative study. Int Emerg Nurs 2018;39:20-5.

10 Li N, Zhang L, Xiao G, et al. The relationship between workplace violence, job satisfaction and turnover intention in emergency nurses. Int Emerg Nurs 2019;45:50-5.

11 Boafo IM, Hancock P. Workplace violence against nurses: a cross-sectional descriptive study of Ghanaian nurses. Sage Open 2016;7:1-9.

12 Hassard J, Teoh KRH, Cox T. Estimating the economic burden posed by work-related violence to society: a systematic review of cost-ofillness studies. Saf Sci 2019;116:208-21.

13 Li Y-F, Chao M, Shih C-T. Nurses' intention to resign and avoidance of emergency department violence: a moderated mediation model. Int Emerg Nurs 2018;39:55-61.

14 López-García C, Ruiz-Hernández JA, Llor-Zaragoza L, et al. User violence and psychological well-being in primary health-care professionals. Eur J Psychol Appl Legal Context 2018;10:57-63.

15 Stewart MW. Workplace violence against nurses. J Perianesth Nurs 2018;33:356-9.

16 Berlanda S, Pedrazza M, Fraizzoli M, et al. Addressing Risks of Violence against Healthcare Staff in Emergency Departments: The Effects of Job Satisfaction and Attachment Style. Biomed Res Int 2019;2019:1-12.

17 Pich JV, Kable A, Hazelton M. Antecedents and precipitants of patient-related violence in the emergency department: results from the Australian vent study (violence in emergency nursing and triage). Australas Emerg Nurs J 2017;20:107-13.

18 Noorana Zahra A, Feng J-Y. Workplace violence against nurses in Indonesian emergency departments. Enfermería Clínica 2018;28:184-90.

19 Pourshaikhian M, Abolghasem Gorji H, Aryankhesal A, et al. A systematic literature review: workplace violence against emergency medical services personnel. Arch Trauma Res 2016;5:e28734.

$20 \mathrm{JC} \mathrm{W}$, Chen HY, Hsieh JL, et al. Enhancing health care personnel's response to ER violence using situational simulation. Clin Simul Nurs 2019;28:6-14.

21 Zhang L, Wang A, Xie X, et al. Workplace violence against nurses: a cross-sectional study. Int J Nurs Stud 2017;72:8-14.

22 Ashton RA, Morris L, Smith I. A qualitative meta-synthesis of emergency department staff experiences of violence and aggression. Int Emerg Nurs 2018;39:13-19.

23 Chang HE, Park MY, Jang $\mathrm{H}$, et al. Relationships among demands at work, aggression, and verbal abuse among registered nurses in South Korea. Nurs Outlook 2019;67:567-77. 
24 Kleissl-Muir S, Raymond A, Rahman MA. Incidence and factors associated with substance abuse and patient-related violence in the emergency department: a literature review. Australas Emerg Care 2018:21:159-70.

25 Wolf LA, Delao AM, Perhats C. Nothing changes, nobody cares: understanding the experience of emergency nurses physically or verbally assaulted while providing care. J Emerg Nurs 2014;40:305-10.

26 Wressell JA, Rasmussen B, Driscoll A. Exploring the workplace violence risk profile for remote area nurses and the impact of organisational culture and risk management strategy. Collegian 2018;25:601-6.

27 Nowrouzi-Kia B, Isidro R, Chai E, et al. Antecedent factors in different types of workplace violence against nurses: a systematic review. Aggress Violent Behav 2019;44:1-7.

28 Yoo HJ, Suh EE, Lee SH, et al. Experience of violence from the clients and coping methods among intensive care unit nurses working in a hospital in South Korea. Asian Nurs Res 2018;12:77-85.

29 Molero Jurado MDM, Pérez-Fuentes MDC, Oropesa Ruiz NF, et al. Self-Efficacy and emotional intelligence as predictors of perceived stress in nursing professionals. Medicina 2019;55:237-14.

30 Pulopulos MM, Hidalgo V, Puig-Pérez S, et al. Psychophysiological response to social stressors: relevance of sex and age. Psicothema 2018;30:171-6.

31 Berghoff CR, Tull MT, DiLillo D, et al. The role of experiential avoidance in the relation between anxiety disorder diagnoses and future physical health symptoms in a community sample of young adult women. J Cont Behav Sci 2017;6:29-34.

32 Escobar Jl, Cook B, Chen C-N, et al. Whether medically unexplained or not, three or more concurrent somatic symptoms predict psychopathology and service use in community populations. $J$ Psychosom Res 2010;69:1-8.

33 Niles AN, Dour HJ, Stanton AL, et al. Anxiety and depressive symptoms and medical illness among adults with anxiety disorders. J Psychosom Res 2015;78:109-15.

34 Sanna L, Stuart AL, Pasco JA, et al. Physical comorbidities in men with mood and anxiety disorders: a population-based study. BMC Med 2013;11:110.

35 Weeks P, Hayley A, Stough C. Do individual differences in state and trait anxiety predict sleep difficulties in healthy older adults? Pers Individ Dif 2019;144:141-6.

36 Creed F, Tomenson B, Chew-Graham C, et al. The associated features of multiple somatic symptom complexes. J Psychosom Res 2018;112:1-8.

37 Ortego G, Villafañe JH, Doménech-García V, et al. Is there a relationship between psychological stress or anxiety and chronic nonspecific neck-arm pain in adults? A systematic review and metaanalysis. J Psychosom Res 2016;90:70-81.

38 Gu B, Tan Q, Zhao S. The association between occupational stress and psychosomatic wellbeing among Chinese nurses: a crosssectional survey. Medicine 2019;98:e15836.

39 Blouin AS, Smith-Miller CA, Harden J, et al. Caregiver fatigue: implications for patient and staff safety, part 1. J Nurs Adm 2016;46:329-35.

40 Johnson J, Hall LH, Berzins K, et al. Mental healthcare staff wellbeing and burnout: A narrative review of trends, causes, implications, and recommendations for future interventions. Int J Ment Health Nurs 2018;27:20-32.

41 Dijkstra-Kersten SMA, Sitnikova K, van Marwijk HWJ, et al. Somatisation as a risk factor for incident depression and anxiety. $J$ Psychosom Res 2015;79:614-9.

42 Seun-Fadipe CT, Akinsulore AA, Oginni OA. Workplace violence and risk for psychiatric morbidity among health workers in a tertiary health care setting in Nigeria: prevalence and correlates. Psychiatry Res 2019;272:730-6.

43 Utzon-Frank N, Breinegaard N, Bertelsen M, et al. Occurrence of delayed-onset post-traumatic stress disorder: a systematic review and meta-analysis of prospective studies. Scand J Work Environ Health 2014:40:215-29.

44 Lowe SR, Joshi S, Galea S, et al. Pathways from assaultive violence to post-traumatic stress, depression, and generalized anxiety symptoms through stressful life events: Iongitudinal mediation models. Psychol Med 2017;47:2556-66.

45 Pihl-Thingvad J, Andersen LL, Brandt LPA, et al. Are frequency and severity of workplace violence etiologic factors of posttraumatic stress disorder? A 1-year prospective study of 1,763 social educators. J Occup Health Psychol 2019;24:543-55.

46 Rudkjoebing LA, Bungum AB, Flachs EM, et al. Work-Related exposure to violence or threats and risk of mental disorders and symptoms: a systematic review and meta-analysis. Scand J Work
Environ Health 2020. doi:10.5271/sjweh.3877. [Epub ahead of print: 07 Jan 2020].

47 Lo T, De Stefano L, SH L, et al. Post-Traumatic stress disorder in resident physicians. Curues 2019;11:e4816.

48 Hosseininejad SM, Jahanian F, Elyasi F, et al. The prevalence of post-traumatic stress disorder among emergency nurses: a cross sectional study in northern Iran. Biomed 2019;9:19-31.

49 Fattah Moghaddam L, Memari A, Bamdad M. Psychological and physical impact of violence in psychiatric nurses. Eur Psychiat 2017:41:S682.

50 van Steijn ME, Scheepstra KWF, Yasar G, et al. Occupational wellbeing in pediatricians-a survey about work-related posttraumatic stress, depression, and anxiety. Eur J Pediatr 2019;178:681-93.

51 Shi L, Li G, Hao J, et al. Psychological depletion in physicians and nurses exposed to workplace violence: a cross-sectional study using propensity score analysis. Int J Nurs Stud 2019;103:103493.

52 Lu L, Lok K-I, Zhang L, et al. Prevalence of verbal and physical workplace violence against nurses in psychiatric hospitals in China. Arch Psychiatr Nurs 2019;33:68-72.

53 Zhao S, Xie F, Wang J, et al. Prevalence of workplace violence against Chinese nurses and its association with mental health: a cross-sectional survey. Arch Psychiatr Nurs 2018;32:242-7.

54 Portoghese I, Galletta M, Leiter MP, et al. Fear of future violence at work and job burnout: a diary study on the role of psychological violence and job control. Burnout Res 2017;7:36-46.

55 Coskun Cenk S. An analysis of the exposure to violence and burnout levels of ambulance staff. Turk J Emerg Med 2019;19:21-5.

56 Llosa JA, Menéndez-Espina S, Agulló-Tomás E, et al. Job insecurity and mental health:A meta-analytical review of the consequences of precarious work in clinical disorders. An Psicol 2018;36:211-23.

57 Kim LY, Rose DE, Ganz DA, et al. Elements of the healthy work environment associated with lower primary care nurse burnout. Nurs Outlook 2020;68:14-25.

58 Pérez-Fuentes MdelC, Molero-Jurado MdelM, Gázquez-Linares JJ, et al. Analysis of burnout predictors in nursing: risk and protective psychological factors. Eur J Psychol Appl 2019;11:33-40.

59 Giannouli V. Towards a more complex perspective on workplace violence: More to come? Commentary on Zhang et al., 2017 "Workplace violence against nurses: A cross-sectional study". Int $J$ Nurs Stud 2018;77:27-8

60 Muglia S, Bneson N, de Lara W, et al. Adult temperament styles: a network analysis of their relationships with the big five personality model. Eur J Educ Psychol 2018;11:61-75.

61 Buela-Casal G, Guillén-Riquelme A. Short form of the Spanish adaptation of the State-Trait anxiety inventory. Int $J$ Clin Health Psychol 2017;17:261-8.

62 Martos África, Pérez-Fuentes MdelC, Molero MdelM, et al. Burnout Y engagement en estudiantes de Ciencias de la Salud. Eur J Investig Health Psychol Educ 2018;8:23-36.

63 Escribano RB, Beneit J, Luis Garcia J, et al. Violence in the workplace: some critical issues looking at the health sector. Heliyon 2019;5:e01283.

64 Pérez-Fuentes MDC, Molero Jurado MDM, Barragán Martín AB, et al Association with the quality of sleep and the mediating role of eating on self-esteem in healthcare personnel. Nutrients 2019;11:321-10.

65 Consejo General de Colegios Oficiales de Enfermería de España. Informe de las agresiones en el ámbito sanitario 2018 [Report of the aggressions in the health field], 2019. Available: https://www. consejogeneralenfermeria.org/observatorio-enfermero/agresiones/ estadistica-de-agresiones

66 Travetto C, Daciuk N, Fernández S, et al. Agresiones hacia profesionales en el ámbito de la salud. Rev Panam Salud Publica 2015;38:307-15.

67 Taylor S, Zvolensky MJ, Cox BJ, et al. Robust dimensions of anxiety sensitivity: development and initial validation of the anxiety sensitivity Index-3. Psychol Assess 2017;19:176-88

68 Sandín B, Valiente RM, Chorot P, et al. ASI-3 : Nueva escala para la evaluación de la sensibilidad a la ansiedad. Revista de Psicopatología y Psicología Clínica 2007;12:91-104.

69 Spence JT, Helmreich RL, Pred RS, et al. Impatience versus achievement strivings in the type a pattern: differential effects on students' health and academic achievement. J Appl Psychol 1987;72:522-8.

70 Schat ACH, Kelloway EK, Desmarais S. The physical health questionnaire (PHQ): construct validation of a self-report scale of somatic symptoms. J Occup Health Psychol 2005;10:363-81.

71 Cohen J. Statistical power analysis for the behavioral sciences. New York, NY: Routledge Academic, 1988

72 Hayes AF. Introduction to mediation, moderation, and conditional process analysis: a Regression-Based approach. New York, EE.UU: The Guilford Press, 2013. 
73 Lorenzo-Seva U, Ferrando PJ. Factor: un programa de computadora para ajustarse al modelo de análisis factorial exploratorio. Behav Res Methods 2006;38:88-91.

74 Domínguez-Lara S. Fiabilidad Y alfa ordinal. Acta Urolog Español 2018;42:140-1.
75 Elosua P, Zumbo BD. Coeficientes de fiabilidad para escalas de respuesta categórica ordenada. Psicothema 2008;20:896-901.

76 JohnsonR, PennyJ, FiabilidadS-H. Dividir confi -la mitad bilidad. In: Kempf-LeonardK, ed. Enciclopedia de la medida social. Ámsterdam, Países Bajos: Elsevier, 2005: 649-54. 